\title{
A Turbine-powered UAV Controls Testbed
}

\author{
Mark A. Motter ${ }^{*}$ and James W. High ${ }^{\dagger}$ \\ NASA Langley Research Center, Hampton, Virginia, 23681 \\ Nelson M. Guerreiro ${ }^{\ddagger}$ \\ National Institute of Aerospace, Hampton, VA 23666 \\ Ryan S. Chambers ${ }^{\S}$ and Keith D. Howard ${ }^{* *}$ \\ United States Naval Academy, Annapolis, Maryland 21402
}

The latest version of the NASA Flying Controls Testbed (FLiC) integrates commercialoff-the-shelf components including airframe, autopilot, and a small turbine engine to provide a low cost experimental flight controls testbed capable of sustained speeds up to $200 \mathrm{mph}$. The series of flight tests leading up to the demonstrated performance of the vehicle in sustained, autopiloted 200 mph flight at NASA Wallops Flight Facility's UAV runway in August 2006 will be described. Earlier versions of the FLiC were based on a modified Army target drone, AN/FQM-117B, developed as part of a collaboration between the Aviation Applied Technology Directorate at Fort Eustis, Virginia and NASA Langley Research Center. The newer turbine powered platform (J-FLiC) builds on the successes using the relatively smaller, slower and less expensive unmanned aerial vehicle developed specifically to test highly experimental flight control approaches with the implementation of C-coded experimental controllers. Tracking video was taken during the test flights at Wallops and will be available for presentation at the conference. Analysis of flight data from both remotely piloted and autopiloted flights will be presented. Candidate experimental controllers for implementation will be discussed. It is anticipated that flight testing will resume in Spring 2007 and those results will be included, if possible.

\section{Nomenclature}

$\begin{array}{ll}\text { Fps } & =\text { feet per second } \\ \text { Mph } & =\text { miles per hour } \\ \text { FLiC } & =\text { Flying Controls Testbed } \\ \text { J-FLiC } & =\text { Jet-powered Flying Controls Testbed } \\ \text { AirSTAR } & =\text { Airborne Subscale Transport Aircraft Research Testbed } \\ \text { SOM } & =\text { Self Organizing Map } \\ \text { UAV } & =\text { unmanned aerial vehicle }\end{array}$

\section{Disclaimer}

Reference herein to any specific commercial products, process, or service by trade name, trademark, manufacturer, or otherwise, does not necessarily constitute or imply its endorsement, recommendation, or favoring by the United States Government. The views and opinions of authors expressed herein do not necessarily state or reflect those of the United States Government, and shall not be used for advertising or product endorsement purposes.

\footnotetext{
${ }^{*}$ Controls Research Engineer, Electronic Systems Branch, Mail Stop 488, Member, AIAA, Senior Member IEEE.

${ }^{\dagger}$ Engineering Technician, Electronics System Branch, Mail Stop 488.

${ }^{\ddagger}$ Graduate Research Associate, NIA/University of Maryland, 100 Exploration Way, Member, AIAA.

$\S$ Midshipman First Class, Aerospace Engineering Department

** Midshipman Second Class, Aerospace Engineering Department
} 


\section{Introduction}

The NASA Flying Controls Testbed (FLiC) project proposed to conceive, develop, implement, and flight test highly experimental and perhaps even controversial flight control technologies in a relatively low cost and low risk platform. Early efforts in the program focused on developing an inexpensive, small, relatively slow test platform controlled by a commercially available autopilot capable of stabilizing, navigating, and recording flight data This initial version of the FLiC was based on the AN/FQM-117B, a surplus Army target drone provided by the Applied Aviation Technology Directorate at Fort Eustis, Virginia. The FLiC served as the experimental testbed for selforganizing map (SOM) based multiple-model controllers [1] as well as a training and development platform for both remotely piloted and autonomous flight operations. On June $27^{\text {th }}$, 2005, the FLiC performed a fully autonomous flight test demo at the Association for Unmanned Systems International (AUVSI) UAV Demo 2005, held at Naval Auxiliary Landing Field, Webster Field, MD .

Concurrently, another NASA project, AirSTAR, was pursuing the goal of testing control upset recovery programs on a dynamically scaled transport model. AirSTAR is an unmanned, remotely piloted, $5.5 \%$ (seven foot wingspan), twin turbine, generic transport aircraft with a sophisticated instrumentation and telemetry package[2]. Currently, AirSTAR is remotely piloted by direct visual observation with plans in the near future to be operated with

\begin{tabular}{|l|l|}
\hline Wingspan: & $80{ }^{\prime}$ \\
\hline Length: & $94{ }^{\prime}$ \\
\hline Weight: & $40 \mathrm{lbs}$ \\
\hline Wing Area: & $1600 \mathrm{in}^{2}$ \\
\hline Wing Loading: & $58 \mathrm{oz} . \mathrm{ft}^{2}$ \\
\hline Thrust: & $26 \mathrm{lbs}$ \\
\hline Speed Range: & $35-200 \mathrm{mph}$ \\
\hline
\end{tabular}

Table 1. J-FLiC airframe specifications ground based computers providing augmented control, based on telemetered data (downlink) and control commands (uplink), to research pilots seated in a virtual cockpit. In support of the AirSTAR project, it was desired to investigate the feasibility of using commercially available autopilots for operations beyond the visual range of the safety pilot and to mitigate the consequences of a lost command link. These goals were well aligned with advancing the capability of FLiC, particularly in regards to speed and altitude. The resulting collaboration resulted in the development of J-FliC, a jet powered version of the FLiC.

\section{Platform Description}

J-FLiC essentially uses the same avionics, i.e. autopilot, radio modem, RC receiver and UAV safety switch, as it's prop-version predecessor, described in detail in [3]. The fundamental difference is in the airframe, engine, and

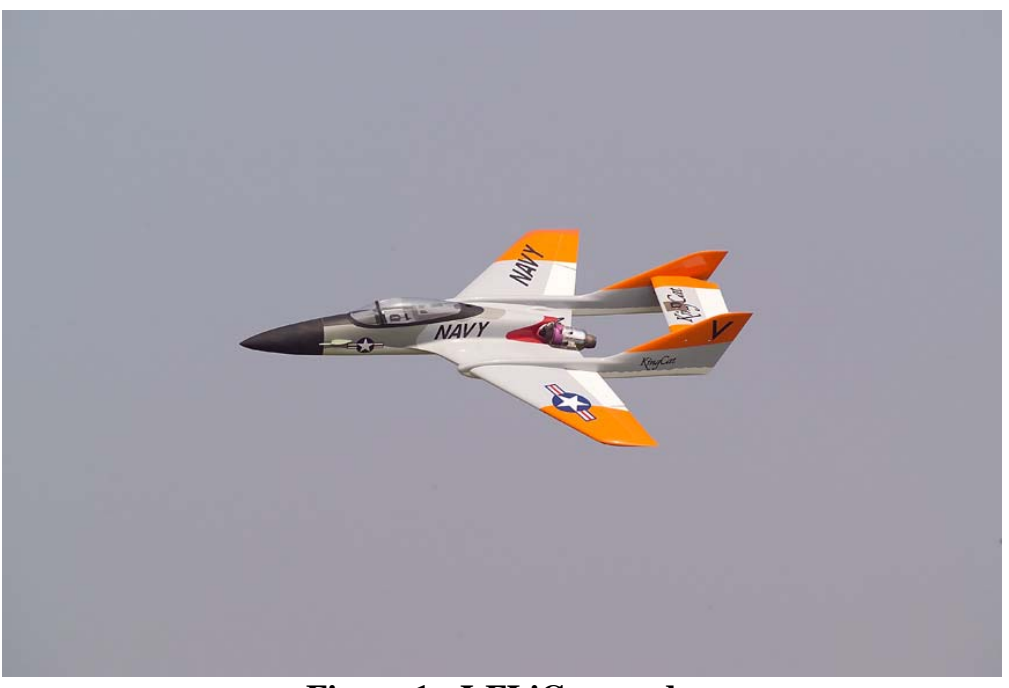

Figure 1. J-FLiC up and away autopilot control gains and settings. The airframe is the commercially available Bob Violett Models (BVM) KingCat. The KingCat has been used extensively for safety pilot training in the AirSTAR program. It is well behaved at both high and low speeds, recovers from spins and stalls predictably, is highly visible, particularly in the orange-tipped Navy paint scheme, and is easily repaired from readily available spare parts. The AirSTAR program has logged several hundred flights on various KingCat airframes equipped with JetCat P-120 engines. The P-120 nominally produces 26 pounds of thrust, providing takeoff distances on the order of 400 feet, climb rates in excess of $2000 \mathrm{fpm}$ and sustained speeds of $200 \mathrm{mph}$ in the KingCat. Table 1 shows the pertinent specifications and J-FLiC is shown in flight in Figure 1. J-FLiC has completed more than 50 flights as of April 2007., with approximately half of those flights engaging autopilot control during some segment of the flight. 




Figure 2. NASA Wallops UAV Runway (750 ft x 50 ft, 2004)

\section{Initial Flights}

The initial flights of the J-FLiC airframe were flown in August 2004 at NASA Wallops Flight Facility's UAV Runway, shown in Figure 2. These initial flights were manually piloted, using COTS radio control (RC) equipment, implementing stick-to-surface control with no compensation. A total of seven airframe checkout flights were performed during early Fall 2004 prior to the installation of the autopilot. Initially, the autopilot was installed in the airframe but not connected to the control servos or engine control unit (ECU). Flight data such as airspeed, altitude, attitude, body rates and accelerations were recorded in onboard memory and telemetered to the ground control station for display and storage on disk. Another seven flights were conducted in this configuration. Following those flights the control surface servo and ECU commands from the RC receiver were Y-cables to the autopilot for recording. Two test flights in that configuration were conducted in November 2004.

Setbacks and delays were encountered in 2005. The first flight of 2005, conducted on a blustery day in early January resulted in a hard landing requiring extensive airframe repairs which took slightly over three months to complete. Three checkout flights without the autopilot installed were conducted in April and May of 2005 without incident. During the spring and summer of 2005, the emphasis shifted to demonstrating the SOM-based controllers in the FLiC, participation in the AUVSI's UAV Demo 2005, and the initial flights of AirSTAR's prototype dynamically scaled airframe. Flights of J-FLiC resumed in October 2005. Some minor damage was incurred during an attempted go around initiated with insufficient airspeed. Repairs were effected over the winter months with new hope for progress in the Spring.

A checkout flight of the repairs was conducted in late April 2006 with the autopilot installed but not engaged. The first flight of J-FLiC with autopilot engagement was on May $25^{\text {th }}$, 2006. Initial autopilot engagements were up and away, approximately 600 foot altitude at 80 knots, wings approximately level, nose slightly up, five degrees. Figure 3 shows typical pitch and roll responses immediately after autopilot engagement. Gain adjustments to the autopilot inner loop controllers, i.e. pitch controlled by elevator and roll controlled by ailerons, were adjusted based on a combination of accumulated experience from the FLiC and manufacturer's instructions.


Figure 3. Initial autopilot pitch and roll responses 




Figure 4. Ground Track during initial steady circuits at 80 knots - autopiloted in blue, manually piloted in red

With the adjustments to the inner loop controllers providing well damped pitch and roll responses it was time to proceed on to flying steady circuits within visual range at a moderate airspeed. A typical ground track within visual range is shown in Figure 4, with the autopilot-controlled interval shown in blue, while the remotelypiloted interval of the flight is red. During this phase of the flight tests, the throttle was under manual control, adjusted to maintain airspeed near 80 knots. In addition to inner loop control, altitude and heading were being controlled as cascaded outer loop processes by the autopilot. The altitude loop sends pitch commands to the inner


loop pitch controller and the heading loop sends roll commands too the inner loop roll controller. The desired heading is usually determined by the path required to navigate through a preprogrammed series of waypoints, although the autopilot provides the option for fixed heading commands as input from a command script or from the ground control station. The altitude performance of the autopilot during step changes of desired altitude is shown in Figure 5.

Figure 5. Autopilot altitude control during initial circuits 


\section{Speed Build-up Flights}

After demonstrating the capability to perform steady circuits at 80 knots with good heading, altitude, and attitude control, speed build-up flights were cautiously undertaken with throttle still under manual control This approach served several purposes; first, it enabled both the direct visual observation as well as post-flight analysis of the dynamic control of the vehicle with relatively small and deliberate increments in airspeed; secondly, it provided the basis of a table look-up of throttle settings for a given airspeed in level flight; and it provided a means for reducing speed quickly for any undesired transients while still maintaining autopilot engagement. This phase of the testing illustrated the need for elevator trim changes as a function of airspeed. The significant results of these tests were tables of elevator trim increments, pitch inner loop control gains scheduled with airspeed, adjustment to the limits of integral (trim) contributions to the elevator and throttle commands, and a table of throttle settings based on the desired airspeed. The throttle settings based on desired airspeed table was realized using a C-code program developed earlier for the prop-powered FLiC. The implementation of these user developed programs serves as a template for more advanced control concepts, such as identifying the throttle lag associated with the turbine spool-up and making predictive or adaptive compensation as in [4,5]. Airspeed, altitude, pitch and target pitch from a typical run up to 125 knots during this phase of the testing is shown in Figure 6. Divergence of pitch from the desired pitch is a consequence of slightly insufficient down trim with increasing speed, combined with limited authority of the integral contribution to the inner loop pitch controller. This tendency was considered preferable to excessive down trim or integral action. However, analysis of the data from the speed build up runs was performed to model the trim requirements.


Pitch and Target pitch



Figure 6. Autopilot control during speed build -up run 




Figure 7. Elevator Position Data from June 22 Flight



Figure 8. Elevator Position Data from June 22 Flight
The initial analysis of the difference between the target and current pitch angle versus the current airspeed showed a semi-linear trend. However, since each flight was different and had different flying packages, no two were the same. Some flights seemed to not have any trends at all. It was observed that the linear trends were only found in the higher range of airspeeds, between 120 and $160 \mathrm{ft} / \mathrm{s}$. Figure 7 shows a linear trend of an increase in pitch difference with increasing speed during the initial speed build-up run. The slope of the trend line shows that the difference in pitch angle increases by a tenth of a degree for every additional foot per second. The elevator position was important to investigate since it directly affects the pitch angle. It was noticed that the elevator was increasing in deflection as the airspeed was increased. This means that it was compensating for the fact that the aircraft would have changed altitude if the elevator did not change as the airspeed increased. As the speed of the aircraft increases, it climbs. Therefore the elevator needs to pitch the nose of the plane down in order to maintain altitude.

Figure 8 shows a near linear relationship between the elevator trim and airspeed during the initial speed build-up flight. The slope of the line is approximately 50 fine servo units (fsu) per foot per second (ft/s), This corresponds to a change in elevator trim position corresponding to approximately 5\% of the total elevator travel over the 40 knot change in airspeed from 80 to 120 knots.

After several speed build-up flights were completed, adjustments were made to the elevator trim and throttle position look up tables. Additionally, the inner loop controller gains for elevator from pitch were scheduled so as to be reduced with increasing airspeed. Refinements to the airspeed control were realized using a limited integral correction along with incorporating the data from the test flights. The typical relationship between throttle position and airspeed over the 80-120 knot range is shown in Figure 9. The throttle range is shown in the autopilot's internal units, representing the range from $1 / 3$ to $2 / 3$ full throttle for the airspeed range shown, in level flight. 


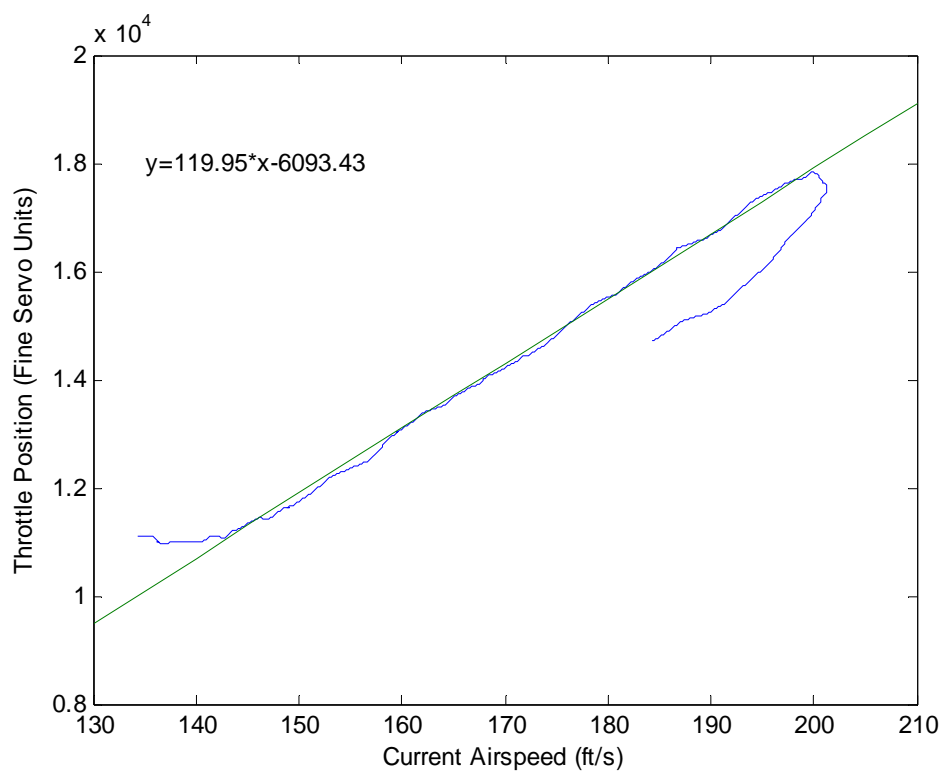

Figure 9. Throttle Position Data from June 22 Flight
During August 2006, another series of speed build-up flights were conducted at NASA Wallops UAV runway. The earlier results were quickly reproduced with noticeably less deviation between the desired pitch and the pitch required to maintain altitude, indicating an improvement in the trim capability. Steady circuits at 800 feet altitude were performed at successively higher speeds, culminating in a sustained full - power run where the speed stabilized at 175 knots, slightly in excess of $200 \mathrm{mph}$. The range requirement to stay within 3000 feet laterally required a nearly steady bank angle of 45 degrees. The ground track for this flight is shown in Figure 10, where it can be seen J-FLiC was well within the prescribed 3000 foot radius. The corresponding flight data is shown flight is shown in Figure 11. Some oscillation in both pitch and roll were observed in the data at the highest speed, but they were bounded and well damped. These results were well correlated with tracking video provided by the range.

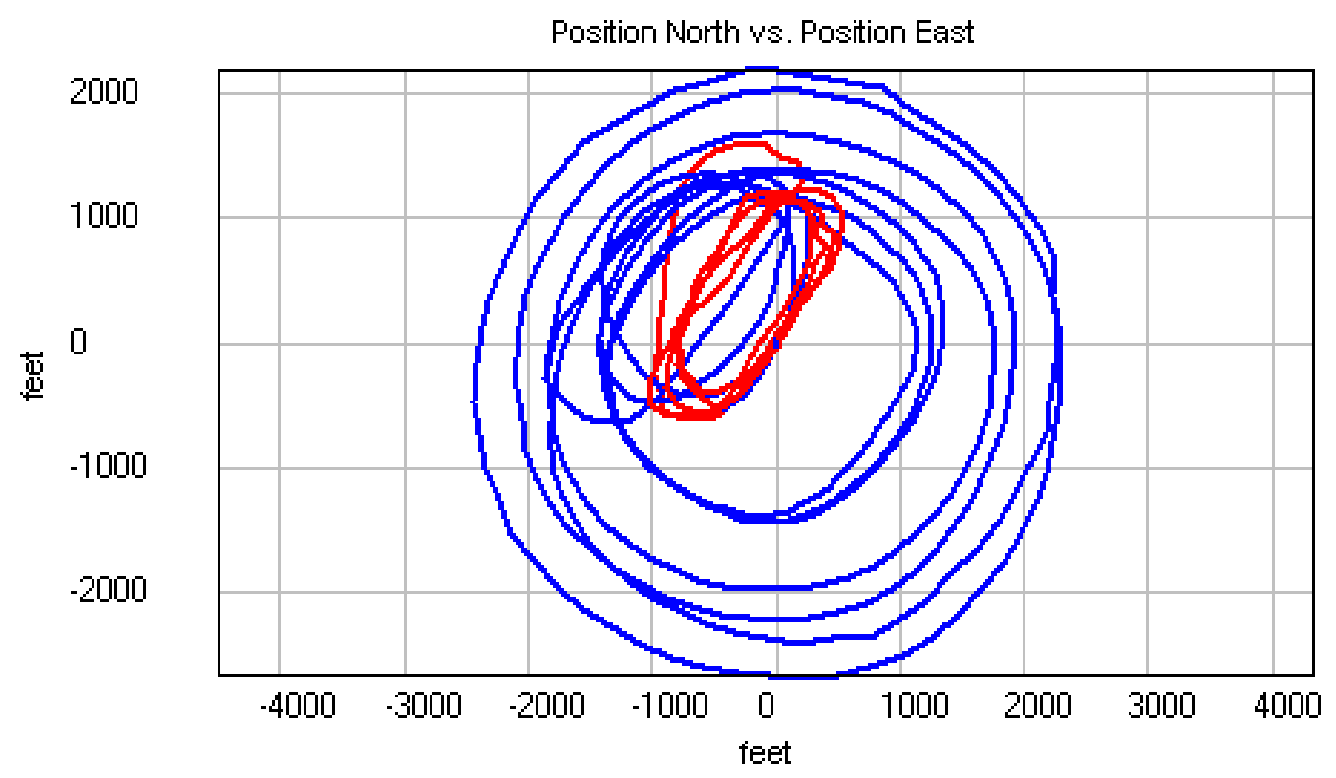

Figure 10. Ground Track during high speed run - autopiloted in blue, manually piloted in red 



Figure 11. Autopilot control during high speed run

\section{Conclusion}

J-FLiC, a turbine powered UAV controls testbed has significantly extended the capabilities of it's prop-powered predecessor, FLiC. The extended speed range can be directly utilized to demonstrate the efficacy of both on-line system identification tools and adaptive control strategies as replacements for simplistic, albeit effective, gain schedules and look up tables. Similar to the evolution of FLiC into J-FLiC, it is anticipated that a slow and steady progression will ultimately lead to the validation of more complex and demanding issues confronting real-time, inflight, on-board adaptive control under parametric uncertainty.

\section{References}

${ }^{1}$ Principe, J.C., Wang, L., Motter, M.A , "Local Dynamic Modeling with Self-Organizing Maps and Applications to Nonlinear System Identification and Control,” Principe, J.C., Wang, L., Motter, M.A., Proceedings of the IEEE, Vol. 86, No. 11, Novemb er 1990.

${ }^{2}$ Jordan, T.L., Foster, J.V.,, Bailey, R.M., and Belcastro, C.M., "AirSTAR: A UAV Platform for Flight Dynamics and

Control System Testing,” 25th AIAA Aerodynamic Measurement Technology and Ground Testing Conference, San Francisco, CA, June 2005

${ }^{3}$ Motter, M.A.,Logan, M.J.,French,M.L. and Guerreiro,N.M., "Simulation to Flight Test for a UAV Controls Testbed," Proceedings of the IEEE, Vol. 78, No. 9, 1990.

${ }^{4}$ Cho, J., Principe, J.C., Erdogmus, D., and Motter, M. A., "Modeling and Inverse Controller Design for an Unmanned Aerial Vehicle Based on the Self-Organizing Map,” IEEE Transactions on Neural Networks, Vol. 17, No. 2, March 2006, pp. 445-460.

${ }^{5}$ Shin, Y., Calise, A.J.., and Motter, M.A.., “Adaptive Autopilot Designs for an Unmanned Aerial Vehicle,” AIAA Guidance, Navigation and Control Conference, AIAA-2003-5312, San Francisco, CA, August 2005 